\title{
CARACTERIZAÇÃO QUÍMICA E EFEITO INIBITÓRIO DE ÓLEOS ESSENCIAIS SOBRE O CRESCIMENTO DE Staphylococcus aureus E Escherichia coli ${ }^{I}$
}

\author{
Chemical ckaracterization and inhibitory effect of essential oils on the growth of \\ Staphylococcus aureus and Escherichia coli
}

\author{
Alcilene de Abreu Pereira² ${ }^{2}$, Maria das Graças Cardoso ${ }^{3}$, Luiz Ronaldo de Abreu ${ }^{4}$, \\ Augusto Ramalho de Morais ${ }^{5}$, Luiz Gustavo de Lima Guimarães ${ }^{6}$, Ana Paula Soares Pinto Salgado ${ }^{7}$
}

\begin{abstract}
RESUMO
Objetivou-se avaliar o efeito inibitório dos óleos essenciais de Cymbopogon citratus (capim-limão), Origanum vulgare (orégano) e Syzygium aromaticum (cravo-da-índia); os experimentos foram realizados com as bactérias Staphylococcus aureus e Escherichia coli, importantes patógenos causadores de contaminações em queijos e outros alimentos. Para quantificação e identificação dos constituintes químicos dos óleos, utilizou-se um cromatógrafo gasoso acoplado a um espectrômetro de massa. Os resultados dos testes in vitro, os óleos essenciais de $C$. citratus, $O$. vulgare e $S$. aromaticum promoveram efeito inibitório sobre as bactérias $S$. aureus e $E$. coli, porém o S. aromaticum apresentou melhor formação de halo de inibição nas menores concentrações. Para o efeito sinergístico dos óleos sobre as bactérias não foram observadas diferenças quando comparados com o efeito individual dos mesmos. Foi possível verificar que os óleos possuem efeito inibitório sobre os microrganismos estudados, sendo, portanto uma alternativa no controle microbiológico de alimentos.
\end{abstract}

Termos para indexação: Óleo essencial, patógenos, constituição química.

\section{ABSTRACT}

With the aim of evaluating the inhinibitory effect of the Cymbopogon citratus (lemon grass), Origanun vulgare (oregano) and Syzygium aromaticum (clove), experiments were performed in laboratories, with the Staphylococcus aureus, Escherichia coli bacteria, important pathogenics which contaminate cheese and other foods. For the oil chemical constitutions quantification and identification, the gas chromatography attached mass spectrometry to a was used. In the results in vitro test, the $C$. citratus, $O$. vulgare and $S$. aromaticum essential oils presented antimicrobian activity over $S$. aureus and E. coli bacteria, however, S. aromaticum presented better formation of inhibition halo in smaller concentrations. For the oil synergetic effect over bacteria and fungi, no significant difference was noticed when compared to their own individual effect. It was possible to verify that the oils had inhibitory effect over the microorganisms studied, being, therefore an alternate option in food microbiological control.

Index terms: Essential oil, pathogenics, chemical component.

(Recebido em 23 de outubro de 2006 e aprovado em 5 de novembro de 2007)

\section{INTRODUÇÃO}

A utilização de produtos naturais que substituam aditivos químicos tem sido uma opção para aqueles que procuram hábitos saudáveis e segurança alimentar. Os óleos essenciais de condimentos possuem comprovada atividade biológica sobre microrganismos, por isso sempre foram utilizados como conservantes de alimentos.

Esses óleos essenciais, extraídos dos vegetais por arraste de vapor de água ou outras técnicas, são compostos de grande importância em pesquisas, por serem potencialmente úteis no controle fitossanitário, propiciando o desenvolvimento de técnicas que procuram diminuir os efeitos negativos de oxidantes, radicais e microrganismos causadores de prejuízos nas indústrias alimentícias (SANTOS, 2004). O uso de metabólitos secundários de plantas vem crescendo e conquistando o mercado e a preferência dos consumidores por apresentarem benefícios à saúde, bem como menores impactos ao meio ambiente. Portanto, a pesquisa

${ }^{1}$ Parte da Dissertação do Autor

${ }^{2}$ Mestre em Ciência dos Alimentos - Departamento de Ciência de Alimentos/DCA - Universidade Federal de Lavras/UFLA - Cx. P. 3037 - $37200-000$ Lavras, MG - alcileneabreu@yahoo.com.br

${ }^{3}$ Doutora em Química - Departamento de Química/DQI - Universidade Federal de Lavras/UFLA - Cx. P. 3037 - $37200-000$ - Lavras, MG/Pesquisadora da UNINCOR/Três Corações - mcardoso@ufla.br

${ }^{4}$ Doutor em Ciência dos Alimentos - Departamento de Ciência de Alimentos/DCA - Universidade Federal de Lavras/UFLA - Cx. P. 3037 - $37200-000$ Lavras, MG - Irabreu@ufla.br

${ }^{5}$ Doutor em Estatística Aplicada à Experimentação Agronômica - Departamento de Ciências Exatas/DEX - Universidade Federal de Lavras/UFLA Cx. P. 3037 - 37200-000 - Lavras, MG - armorais@ufla.br

${ }^{6}$ Mestre - Departamento de Química/DQI - Universidade Federal de Lavras/UFLA - Cx. P. 3037 - 37200-000 - Lavras, MG - luizufop@yahoo.com.br ${ }^{7}$ Doutora em Fitotecnia - Departamento de Química/DQI - Universidade Federal de Lavras/UFLA - Cx. P. 3037 - $37200-000-$

Lavras, MG - apsalgado9@yahoo.com.br 
fitoquímica apresenta-se como um método útil, buscando técnicas analíticas e instrumentais que permitem o isolamento e elucidação de inúmeros compostos. Esses metabólitos possuem potencialidade para uso na indústria alimentícia, nas quais a possibilidade de contaminações é grande. Os alimentos podem transmitir diversos microrganismos, muitas vezes, patógenos para o homem, como as bactérias Staphylococcus aureus e Escherichia coli.

Entre as espécies aromáticas, o Cymbopogon citratus, o Origanum vulgare e o Syzygium aromaticum, conhecidos popularmente por capim-limão, orégano e cravo-da-índia, apresentam inúmeras atividades biológicas, reflexos da diversidade química que possuem (CRAVEIRO et al., 1981). O presente trabalho teve por finalidade avaliar a composição química, o efeito inibitório e sinergístico dos óleos essenciais de C. citratus, $O$. vulgare e $S$. aromaticum sobre o crescimento dos microrganismos $S$. aureus e E. coli.

\section{MATERIAL E MÉTODOS}

O material vegetal fresco $(370 \mathrm{~g}$ de folhas de Cymbopogon citratus) foi coletado no Horto de Plantas Medicinais da Universidade Federal de Lavras (UFLA), em outubro de 2005 às 8 horas, com temperatura em torno de $20^{\circ} \mathrm{C}$ e ausência de chuvas. Foram coletadas as folhas jovens do capim-limão. Os outros materiais vegetais (367g de folhas de Origanum vulgare e $512 \mathrm{~g}$ de inflorescências de Syzygium aromaticum) foram adquiridos no mercado municipal da cidade de Lavras, no mesmo dia da coleta do material fresco. A extração dos óleos essenciais dos vegetais foi realizada no Laboratório de Química Orgânica do Departamento de Química da Universidade Federal de Lavras (UFLA) - Lavras - MG, por meio do método de arraste a vapor, utilizando-se o aparelho de Clevenger modificado.

O material foi acondicionado em balões de 6 litros e o óleo extraído por 3 horas, em temperatura constante, mantendo a ebulição da solução. Decorrido esse tempo, coletou-se o hidrolato, que foi centrifugado a $321,8 \mathrm{x}$ g por 5 minutos. O rendimento do óleo foi calculado e expresso em volume de óleo por peso de folhas frescas (\%v/p) e com base na matéria seca ou Base Livre de Umidade (\%v/ p BLU) (PIMENTEL et al., 2006).

As análises qualitativas para identificação dos constituintes dos óleos essenciais foram realizadas no Laboratório de Análises e Sínteses de Agroquímicos do
Departamento de Química da Universidade Federal de Viçosa (UFV) - Viçosa - MG por cromatografia gasosa acoplada à espectrometria de massa (CG/EM), utilizandose aparelho Shimadzu CG-17A, com detector seletivo de massa modelo QP 5000. O equipamento foi operado nas seguintes condições: coluna capilar de sílica fundida $(30 \mathrm{~m}$ X 0,25mm), com fase ligada DB5 ((5\%-fenil)metilpolisiloxano), com $0,25 \mu \mathrm{m}$ de espessura de filme; temperatura do injetor de $220^{\circ} \mathrm{C}$; programação da coluna com temperatura inicial de $40^{\circ} \mathrm{C}$, sendo acrescidos $3^{\circ} \mathrm{C}$ a cada minuto até atingir $240^{\circ} \mathrm{C}$; gás carreador hélio $(1 \mathrm{~mL}$ $\left.\min ^{-1}\right)$; pressão inicial na coluna de $100,2 \mathrm{KPa}$; taxa de split 1:10 e volume injetado de $1 \mu \mathrm{L}(1 \%$ de solução em diclorometano). Para o espectrômetro de massas (EM) foram utilizadas as seguintes condições: energia de impacto de $70 \mathrm{eV}$; velocidade de decomposição 1000; intervalo de decomposição de 0,50; e fragmentos de $45 \mathrm{Da}$ e 450 Da decompostos. Foi injetado, nas mesmas condições da amostra, uma série de padrões de hidrocarbonetos $\left(\mathrm{C}_{9} \mathrm{H}_{20}\right.$ ....... $\mathrm{C}_{26} \mathrm{H}_{54}$ ). Os espectros obtidos foram comparados com o banco de dados da biblioteca Wiley 229 e pelo índice de Kovat's calculado para cada constituinte de acordo com Adams (1995) e as análises quantitativas foram conduzidas no Laboratório de Química Orgânica do Departamento de Química da Universidade Federal de Lavras (UFLA) Lavras - MG, utilizando cromatógrafo gasoso Shimadzu GC 17A equipado com detector por ionização de chamas (DIC), nas condições operacionais: coluna capilar DB5 ((5\%-fenil)-metilpolisiloxano), com $0,25 \mu \mathrm{m}$ de espessura de filme; programação da coluna com temperatura inicial de $40^{\circ} \mathrm{C}$ até $240^{\circ} \mathrm{C}$; temperatura do injetor de $220^{\circ} \mathrm{C}$; temperatura de detector de $240^{\circ} \mathrm{C}$; gás carreador nitrogênio $\left(2,2 \mathrm{~mL} \mathrm{~min}^{-1}\right)$; taxa de split 1:10 e volume injetado de $1 \mu \mathrm{L}$ (1\% de solução em diclorometano) e pressão na coluna de $115 \mathrm{KPa}$, sendo a quantificação de cada constituinte obtida por meio de normalização de áreas (\%).

As análises microbiológicas dos óleos essenciais foram realizadas no Laboratório de Microbiologia de Alimentos do Departamento de Ciência dos Alimentos da Universidade Federal de Lavras (UFLA) - Lavras - MG. Para a avaliação "in vitro" do efeito inibitório dos óleos de C. citratus (capim-limão), O. vulgare (orégano) e $S$. aromaticum (cravo-da-índia), foram utilizadas as cepas de S. aureus ATCC 25923 e E. coli ATCC 8739. Durante o experimento, os microrganismos foram mantidos em slants de TSA (triptc Soy Agar Merk) em refrigeração $\left(4^{\circ} \mathrm{C}\right)$, repicados em caldo TSB para a ativação das culturas e a 
realização dos ensaios. As culturas ativadas foram repicadas para caldo infusão de cérebro e coração (BHI Oxoid), ficando incubadas a $37^{\circ} \mathrm{C}$ por 24 horas. Após esse período, uma alíquota de $5 \mathrm{~mL}$ foi transferida para o meio de cultura Mueller Hinton, e a metodologia empregada foi a difusão em agar. A concentração de cada óleo foi determinada em relação ao diâmetro do halo de inibição obtido. Os slots ou poços de deposição dos óleos essenciais foram feitos no ágar com o auxilio de pérolas de vidro, retiradas previamente. Em seguida, $8 \mu \mathrm{L}$ dos óleos essenciais foram diluídos em etanol e transferidos para os mesmos.

O ágar Miller Hinton foi inoculado com as culturas reveladoras ( $S$. aureus e $E$. coli) e depositados sobre camada do mesmo ágar onde foram feitos os slots que foram preenchidos com os óleos nas concentrações de 0,$1 ; 0,5 ; 1 ; 5 ; 10 ; 20 ; 30 ; 40$ e 50\%, e para a análise do sinergismo (combinação entre os óleos) foram utilizadas as concentrações 0,$1 ; 1 ; 10 ; 30$ e $50 \%$. As placas foram incubadas em BOD $37^{\circ} \mathrm{C}$ por 48 horas (OGUNWANDE et al., 2005) e medidos os diâmetros dos halos formados. Para a análise estatística utilizou-se o delineamento em blocos casualizados tendo o fator bactérias como blocos $(S$. aureus e E. coli), onde o esquema fatorial foi de $3 \times 9 \times 2$, sendo três óleos essenciais (cravo da índia, orégano e capim-limão), nove concentrações $(0,1,0,5,1,5,10,20,30$, 40 e $50 \%$ ), totalizando 27 tratamentos, com duas repetições.

Para estudo do efeito sinergístico dos óleos essenciais foi realizado o delineamento em blocos casualizados sendo o fator bactérias como blocos $(S$. aureus e $E$. coli), onde o esquema fatorial foi de $3 \times 5 \times 2$, sendo três combinações dos óleos essenciais (capim-limao/ orégano, orégano/cravo-da-índia, cravo-da-índia/capimlimão), cinco concentrações $(0,1,1,10,30$ e 50\%), totalizando 15 tratamentos, com duas repetições. O programa estatístico utilizado foi o SISVAR (FERREIRA, 2000). Quanto à análise de variância, os tratamentos foram submetidos ao teste de Scott-Knott, a 5\% de significância.

\section{RESULTADOS E DISCUSSÃO}

Os principais constituintes do óleo essencial do C. citratus (capim-limão) identificados e quantificados foram neral $(40,2 \%)$, geranial $(31,8 \%)$, que isomericamente formam o citral, mirceno $(19,7 \%)$, neo-mentol $(1,1)$, acetato de linalila $(0,4 \%),(Z)$ - $\beta$-ocimeno $(1,1 \%)$ e (E)- $\beta$-ocimeno $(1,4 \%)$.

Craveiro et al. (1981) avaliando a composição química do óleo essencial dessa planta, identificou que os compostos citral (mistura isomérica de neral e citral) são majoritários e responsáveis pelo aroma cítrico da planta. Sacchetti et al. (2005) comprovou a atividade antimicrobiana do óleo essencial de $C$. citratus, pela análise de seus constituintes químicos por CG/EM. Encontrou, $0,43 \%$ de metil-5-epten-2-ona, 15,48\% de mirceno, $1,28 \%$ de linalol, $32,3 \%$ de neral, $3,35 \%$ de geraniol e $41,3 \%$ de geranial. Esses resultados foram similares aos encontrados para a planta estudada. Algumas variações justificam-se pelas diferenças em razão da época de plantio, tipo de solo, clima entre outros.

A avaliação do óleo essencial de $S$. aromaticum apresentou em sua constituição $86,3 \%$ de eugenol, $8,2 \%$ de trans-cariofileno, $0,8 \%$ de $\alpha$-humuleno e 3,6\% de acetato de eugenila. Oussalah et al. (2006) avaliaram os constituintes do óleo essencial de cravo-da-índia e encontraram as seguintes proporções, $78 \%$ de eugenol e $8 \%$ de acetato de eugenila, confirmando o resultado encontrado para o óleo de cravo-da-índia testado nas bactérias estudadas.

Infere-se portanto que o eugenol, sendo o constituinte majoritário, pode ser o responsável pelo efeito inibitório do óleo essencial de cravo-da-índia sobre bactérias, sendo muito utilizado como antisséptico.

Já para os constituintes do óleo essencial do $O$. vulgare utilizado, as proporções e as substâncias identificadas foram: $0,7 \%$ de $\alpha$-pineno, $1,1 \%$ de $\alpha$ felandreno, $2,7 \%$ de mirceno, $6,9 \%$ de $\alpha$-terpineno, $4,6 \%$ de p-cimeno, 2,3\% de $\beta$-felandreno, $16,6 \%$ de $\beta$-cimeno, $16,0 \%$ de $\gamma$-terpineno, $1,8 \%$ de terpinoleno, $12,3 \%$ de linalol, $26,3 \%$ de terpen-4-ol, 3,8\% de $\alpha$-terpineol, $0,8 \%$ de timol metil éter, $1,6 \%$ de carvacrol metil éter, $1,7 \%$ de acetato de linalila, 7,2\% de carvacrol e 1,3\% de trans-cariofileno.

Milos et al. (2000), pesquisando os constituintes do óleo essencial do orégano, identificou um total de 16 compostos. Entre eles estão 40,4\% de timol, $24,8 \%$ de carvacrol e $16,8 \%$ de p-cimeno, $1,7 \%$ de $\gamma$-terpineno, $2,1 \%$ de 1-octen-3-ol e 2,1\% de borneol, confirmando alguns dos compostos identificados em menor quantidade no óleo essencial de $O$. vulgare utilizado.

A formação do halo de inibição das bactérias $E$. coli ATCC 8739 e S. aureus ATCC 8739, induzidos pelos óleos essenciais de $C$. citratus (capim-limão), $O$. vulgare (orégano) e S. aromaticum (cravo-da-índia) foram medidos e revelaram efeito inibitório para os referidos óleos.

Pelos dados da Tabela 1, observa-se que o efeito do óleo essencial de capim-limão sobre E. coli, não apresentou variação significativa no tamanho do halo nas concentrações de $0,1,0,5,1,5$ e $10 \%$, enquanto nas 
concentrações de 20,30, 40 e 50\%, observou-se uma variação de tamanho em relação aos resultados do primeiro grupo, porém, entre eles os valores mantiveram-se constantes. A placa-controle, constando apenas do solvente etanol, não promoveu formação do halo. O óleo essencial de orégano, não promoveu inibição do crescimento bacteriano na concentração de $0,1 \%$, provavelmente, pela baixa concentração do mesmo. Os outros valores $(0,5,1,5,10,20,30,40$ e 50\%) não apresentaram significativa variação na indução de formação de halo, mas promoveram a formação de halo da bactéria.

O óleo de cravo-da-índia apresentou os melhores resultados de inibição do crescimento entre os óleos, porém não apresentou variação significativa entre as concentrações $0,1,0,5,1$ e $5 \%$, que diferiram das concentrações de 10, 20, 30, 40 e 50\%.

Pelos dados da Tabela 2 observam-se que a avaliação do halo de inibição do $S$. aureus apresentaram resultado similar ao encontrado para E. coli. Em relação ao efeito inibitório do óleo essencial de capim-limão sobre $S$. aureus, as concentrações entre $0,1 \%$ e $20 \%$ não apresentaram significativa variação e encontrou-se constância para os outros valores (30\%, 40\% e 50\%). Os óleos de orégano e cravo-da-índia promoveram formação de halo de inibição em todas as concentrações.

Os dados descritos nas tabelas 1 e 2 sugerem o efeito inibitório dos óleos de capim-limão, orégano e cravo-da-índia. Segundo Cox et al. (2000), a constância entre os resultados observados provavelmente ocorrem por causa da influência do etanol utilizado na diluição dos óleos. Esse solvente pode alterar a entrada do óleo na célula bacteriana, facilitando sua difusão em maiores diluições, porém pouco se conhece a respeito da ação do óleo sobre a estrutura celular bacteriana. Outro fato que pode explicar esse resultado, é a utilização do método para determinação de antibiogramas, não sendo, portanto, específico para efeito inibitório de óleos essenciais, o que pode influenciar na difusibilidade do mesmo.

Burt (2004) trabalhou com o óleo essencial de orégano. Observou que os princípios ativos (timol e o carvacrol), provocam distorção na estrutura física da célula, causando expansão e conseqüente desestabilidade na membrana, modificando sua permeabilidade, desnaturando enzimas essenciais e alterando a força próton motora, por meio de variações no $\mathrm{pH}$ e potencial elétrico.

Pesquisas de Sacchetti (2005) mostraram que o óleo essencial de $C$. citratus promoveu notável inibição no crescimento das leveduras Candida albicans ATCC 48274, Rhodotorula glutinis ATCC 16740, Schizosaccharomyces pombe ATCC 60232, Saccharomyces cerevisiae ATCC 2365 e Yarrowia lypolítica ATCC 16617. O autor atribuiu essa atividade à presença do componente majoritário, o citral, uma mistura isomérica de neral e citral.

Os melhores resultados de inibição, tanto para $E$. coli quanto para $S$. aureus, foram atribuídos ao cravo-daíndia. Craveiro et al. (1981), constatou excelentes resultados para $E$. coli e $S$. aureus , utilizando óleo essencial de cravoda-índia. Atribuiu suas excelentes propriedades bactericidas, ao eugenol, componente majoritário encontrado em 80-90\% no óleo essencial dessa planta. Segundo ele, o eugenol provoca inibição na produção de amilase e proteases pela célula, bem como sua deterioração e lise, sendo que esse princípio ativo é muito usado na odontologia como componente de seladores e outros produtos antissépticos. Atualmente, o eugenol tem sido largamente estudado como conservante de alimentos.

Nas figuras 1 e 2 mostram-se, por diferentes equações de regressão, a progressão da formação do halo de inibição das bactérias submetidas aos diferentes tratamentos.

A concepção de sinergismo tem sido o tema central de muitas discussões em fitoquímica. A interação entre óleos essenciais podem representar uma alternativa para potencialidade da ação dos mesmos, porém, muito ainda precisa ser esclarecido. Estudos de Harris (2002) examinaram a combinação efetiva entre óleos de Melaleuca (Melaleuca alternifolia e Melaleuca quinquenervia) e a fração polar de Manuka (Leptospermum scoparium). Observaram um efeito bactericida superior àquele observado nos óleos estudados individualmente.

Os dados do efeito sinergístico entre os óleos de capim-limão, orégano e cravo-da-índia representam-se na Tabela 3. Observa-se que não houve significativa variação entre a combinação e o comportamento individual dos óleos, constatando que não ocorreu sinergismo entre os mesmos, na proporção estudada. 
Tabela 1 - Resultados médios do efeito inibitório de óleos essenciais sobre E. coli submetida à diferentes concentrações.

\begin{tabular}{ccccc}
\hline \multirow{2}{*}{ Bactérias } & Concentração & \multicolumn{3}{c}{ Formação do halo de inibição (cm) } \\
\cline { 2 - 4 } & $(\%)$ & Capim-limão & Orégano & Cravo-da-índia \\
\hline \multirow{2}{*}{ E. coli } & 0,1 & $0,7 \mathrm{~b}$ & $0,0 \mathrm{~b}$ & $0,8 \mathrm{~b}$ \\
& 0,5 & $0,7 \mathrm{~b}$ & $0,6 \mathrm{a}$ & $0,9 \mathrm{~b}$ \\
& 1 & $0,8 \mathrm{~b}$ & $0,8 \mathrm{a}$ & $0,9 \mathrm{~b}$ \\
& 5 & $0,8 \mathrm{~b}$ & $0,8 \mathrm{a}$ & $1,0 \mathrm{~b}$ \\
& 10 & $0,8 \mathrm{~b}$ & $0,9 \mathrm{a}$ & $1,1 \mathrm{a}$ \\
& 20 & $1,1 \mathrm{a}$ & $0,9 \mathrm{a}$ & $1,2 \mathrm{a}$ \\
& 30 & $1,2 \mathrm{a}$ & $0,9 \mathrm{a}$ & $1,2 \mathrm{a}$ \\
\hline
\end{tabular}

Médias seguidas com a mesma letra minúscula não diferem significativamente entre si a 1\% de probabilidade, pelo teste de Scott-Knott.

Tabela 2 - Resultados médios do efeito inibitório de óleos essenciais sobre $S$. aureus, submetida à diferentes concentrações.

\begin{tabular}{ccccc}
\hline Bactérias & Concentração & \multicolumn{3}{c}{ Formação do halo de inibição (cm) } \\
\cline { 2 - 4 } & $(\%)$ & Capim-limão & Orégano & Cravo-da-índia \\
\hline & 0,1 & $0,6 \mathrm{~b}$ & $0,8 \mathrm{~b}$ & $1,0 \mathrm{c}$ \\
& 0,5 & $0,6 \mathrm{~b}$ & $0,9 \mathrm{~b}$ & $1,1 \mathrm{c}$ \\
& 1 & $0,6 \mathrm{~b}$ & $1,0 \mathrm{~b}$ & $1,1 \mathrm{c}$ \\
& 5 & $0,7 \mathrm{~b}$ & $1,0 \mathrm{~b}$ & $1,1 \mathrm{c}$ \\
& 10 & $0,8 \mathrm{~b}$ & $1,0 \mathrm{~b}$ & $1,1 \mathrm{c}$ \\
& 20 & $0,8 \mathrm{~b}$ & $1,0 \mathrm{~b}$ & $1,1 \mathrm{c}$ \\
& 30 & $0,9 \mathrm{a}$ & $1,0 \mathrm{~b}$ & $1,3 \mathrm{~b}$ \\
\end{tabular}

Médias seguidas com a mesma letra minúscula não diferem significativamente entre si a 1\% de probabilidade, pelo teste de Scott-Knott.

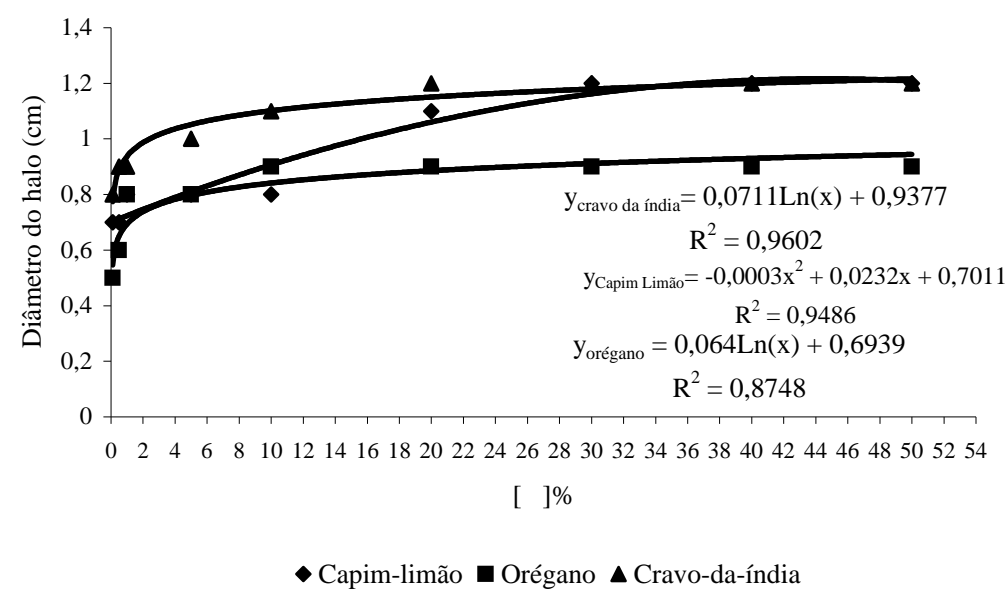

Figura 1 - Tamanho dos halos de inibição de Staphylococcus aureus provocados pelos óleos essenciais. 


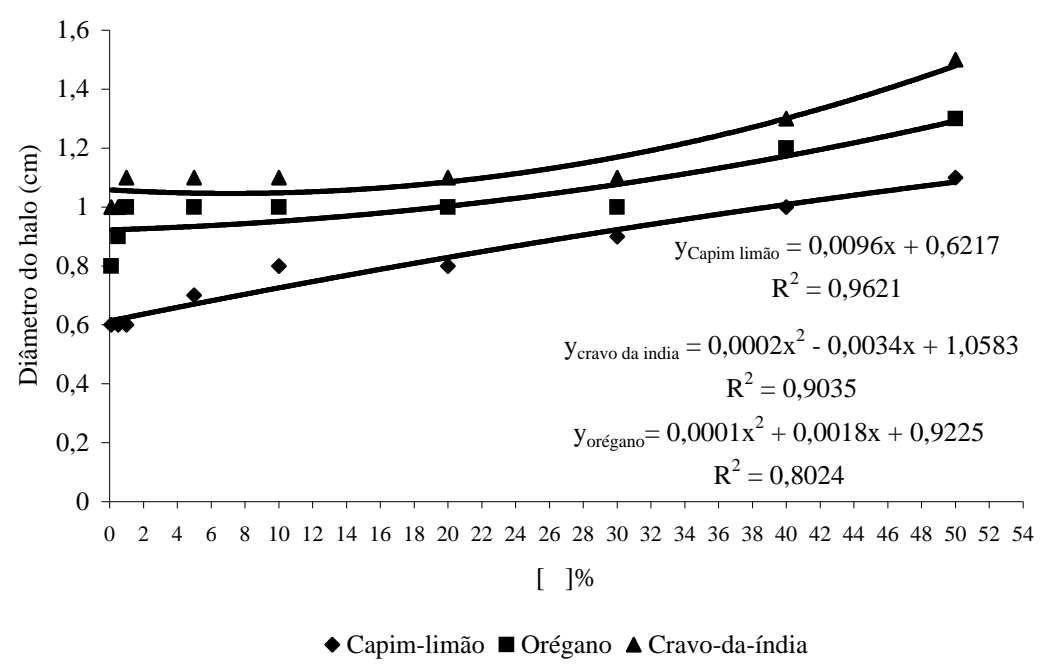

Figura 2 - Tamanho dos halos de inibição de Escherichia coli provocados pelos óleos essenciais.

Tabela 3 - Resultados médios da avaliação do efeito sinergistico dos óleos estudados sobre a formação de halo de inibição, pelas duas espécies de bactérias submetidas à diferentes concentrações.

\begin{tabular}{|c|c|c|c|c|}
\hline \multirow[t]{2}{*}{ Bactérias } & \multirow{2}{*}{$\begin{array}{c}\text { Concentração } \\
\text { de óleo essencial } \\
(\%)\end{array}$} & \multicolumn{3}{|c|}{ Formação do halo de inibição $(\mathrm{cm})$} \\
\hline & & $\begin{array}{c}\text { Capim-limão } \\
+ \\
\text { Orégano }\end{array}$ & $\begin{array}{c}\text { Orégano } \\
+ \\
\text { Cravo-da-índia }\end{array}$ & $\begin{array}{c}\text { Cravo-da-índia } \\
+ \\
\text { Capim-limão }\end{array}$ \\
\hline \multirow[t]{5}{*}{ E. coli } & 0,1 & $0,6 \mathrm{~b}$ & $0,8 \mathrm{~b}$ & $0,7 \mathrm{c}$ \\
\hline & 1 & $0,6 \mathrm{~b}$ & $0,8 \mathrm{~b}$ & $0,7 \mathrm{c}$ \\
\hline & 10 & $0,7 \mathrm{~b}$ & $0,9 \mathrm{~b}$ & $0,9 \mathrm{~b}$ \\
\hline & 30 & $0,9 \mathrm{a}$ & $0,9 \mathrm{~b}$ & $1,1 \mathrm{a}$ \\
\hline & 50 & $0,95 \mathrm{a}$ & $0,9 \mathrm{~b}$ & $1,1 \mathrm{a}$ \\
\hline \multirow[t]{5}{*}{ S. aureus } & 0,1 & $0,7 \mathrm{~b}$ & $0,7 \mathrm{~b}$ & $0,8 \mathrm{~b}$ \\
\hline & 1 & $0,7 \mathrm{~b}$ & $0,7 \mathrm{~b}$ & $0,8 \mathrm{~b}$ \\
\hline & 10 & $0,8 \mathrm{~b}$ & $0,8 \mathrm{~b}$ & $0,9 \mathrm{~b}$ \\
\hline & 30 & $0,9 \mathrm{a}$ & $0,8 \mathrm{~b}$ & $1,1 \mathrm{a}$ \\
\hline & 50 & $0,9 \mathrm{a}$ & $0,9 \mathrm{~b}$ & $1,2 \mathrm{a}$ \\
\hline
\end{tabular}

Médias seguidas com a mesma letra minúscula não diferem significativamente entre si a 1\% de probabilidade, pelo teste de Scott-Knott.

\section{CONCLUSÕES}

Os óleos essenciais de C. citratus, $O$. vulgare e $S$. aromaticum apresentaram efeito inibitório sobre as bactérias $S$. aureus e E. coli. Não houve efeito sinergístico entre os óleos estudados.

\section{AGRADECIMENTOS} concedidas.

\section{REFERÊNCIAS BIBLIOGRÁFICAS}

ADAMS, R. P. Identification of essential oils components by gas chromatography/mass spectroscopy. Carol Stream: Allured, 1995. 469 p.

BURT, S. Essential oils: their antibacterial properties and potential applications in foods: a review. International Journal of Food Microbiology, Amsterdam, v. 94, n. 3, p. 223-253, Aug. 2004. 
COX, S. D.; MANN, C. M.; MARKHAM, J. L.; BELL, H. C.; GUSTAFSON, J. E.; WARMINTON, J. R.; WYLLIE, S. $\mathrm{G}$. The mode of antimicrobial action of the essential oil of Meleuca alternifolia (tea tree oil). Journal of Applied Microbiology, Oxford, v. 88, n. 1, p. 170-175, Jan. 2000.

CRAVEIRO, A. A.; FERNANDES, A. G.; ANDRADE, C. H. S.; MATOS, F. J. A.; ALENCAR, J. W.; MACHADO, M. I. L. Óleos essenciais de plantas do Nordeste. Fortaleza: UFC, 1981. $210 \mathrm{p}$.

FERREIRA, D. F. Análises estatisticas por meio do Sisvar para o Windows versao 4.0. In: REUNIAO ANUAL DA REGIAO BRASILEIRA DA SOCIEDADE INTERNACIONAL DE BIOMETRIA, 45., 2000, São Carlos. Programas e Resumos... Sao Carlos: UFSCar, 2000. p. 255-258.

HARRIS, R. Synergism in the essential oil word. The International Journal of Aromatherapy, Amsterdam, v. 12, n. 4, p. 179-186, Oct./Dec. 2002.

MILOS, M.; MASTELIC, J.; JERKOVIC, I. Chemical composition and antioxidant effect of glycosidically bound volatile compounds from orégano (Origanum vulgare L. ssp. hirtum). Food Chemistry, Oxford, v. 71, n. 1, p. 79-83, Oct. 2000.

OGUNWANDE, I. A.; OLAWORE, N. O.; EKUNDAYO, O.; WALKER, T. M.; SCHIMIDT, J. M.; SETZER, W. N.
Studies on the essential oils composition, antibacterial and cytotoxicity of Eugenia uniflora L. The International Journal of Aromatherapy, Amsterdam, v. 15, n. 3, p. 147 152, Jan. 2005.

OUSSALAH, M.; CAILLET, S.; SAUCIER, L.; LACROIX, M. Inhibitory effects of selected plant essential oils on the growth of four pathogenic bacteria: E. coli 0157:H7, Salmonella typhimurium, Spaphylococcus aureus e Listerria monocytogenes. Food Control, [S.1.], 2006.

PIMENTEL, F. A.; CARDOSO, M. G.; SALGADO, A. P. S. P.; AGUIAR, P. M.; SILVA, V. F.; MORAIS, A. R.; NELSON, D. L. A convenient method for the determination of moisture in aromatic plants. Química Nova, São Paulo, v. 29, n. 2, p. 373-375, mar./abr. 2006.

SACCHETTI, G.; MAIETTI, S.; MUZZOLI, M.; SCAGLIANTI, M.; MANFREDINI, S.; RADICE, M.; BRUNI, R. Comparative evaluation of 11 essential oils of diferent origin as functional antioxidants, antiradicals and antimicrobials in foods. Food Chemistry, Oxford, v. 91, n. 4, p. 621-632, Aug. 2005.

SANTOS, R. I. Metabolismo básico e origem dos metabólitos secundários. In: SIMÕES, C. M. O.; SCHENKEL, E. P.; GOSMANN, G.; MELLO, J. C. P.; MENTZ, L. A.; PETROVICK, P. R. Farmacognosia: da planta ao medicamento. 5. ed. Porto Alegre: UFSC, 2004. 1102 p. 